\title{
Investigating communicative barriers on construction industry productivity in Malaysia: An overview
}

\author{
Khairul Firdaus Ne'Matullah', Lim Seong Pek ${ }^{2}$, Siti Aisyah Roslan ${ }^{3}$ \\ ${ }^{1,3}$ Centre for Foundation and General Studies, Universiti Selangor, Malaysia \\ ${ }^{2}$ Faculty of Education and Social Sciences, Universiti Selangor, Malaysia
}

\section{Article Info \\ Article history: \\ Received Oct 29, 2020 \\ Revised Mar 23, 2021 \\ Accepted Apr 10, 2021 \\ Keywords: \\ Communication \\ Construction industry \\ Cross-cultural \\ Language needs}

\begin{abstract}
The evolution of technology has changed the way how human communicate in the current time. With the advancement of technology, instructions and messages could be delivered in a split second. Even though life is made easy with technology, some information and details should be delivered face-toface in order to avoid communication breakdown. This study was carried out to determine the language needs by foreign workers working at construction sectors in Malaysia. The study created an overview on how communication affects productivity in completing tasks on time. The results from this study lead to a development of language modules for foreign workers training. An online survey was carried out through social media on construction site supervisors around Malaysia in getting their feedback related to the origin of their co-workers and the importance of English language as medium of instruction for task fulfilment. Results indicated that language barriers had affected productivity in the sector of construction in Malaysia. Besides, results also noted that cross-cultural differences had put foreign workers at risk and caused wastage to time and manpower.
\end{abstract}

This is an open access article under the CC BY-SA license.

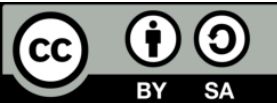

\section{Corresponding Author:}

Khairul Firdaus Ne'Matullah

Centre for Foundation and General Studies

Universiti Selangor

Bestari Jaya Campus, Selangor Darul Ehsan, Malaysia

Email: kfirdaus@unisel.edu.my

\section{INTRODUCTION}

Communication is an integral aspect of our lives where we communicate to get the messages delivered and also to ensure that we are able to comprehend what is being said. Effective communication is important to ensure projects are successful in terms of time and cost management [1]. It is especially essential in construction sites where majority of the processes depends on the communication quality [2]. Similarly, effective communication has a significant role that would affect the outcome of the project in construction sites [3].

However, the influx of foreign workers into the construction industry in Malaysia is worrying as it could lead to various problems in the future. One of the problems is a severe barrier in language skills, which does not help them to be able to communicate effectively [4] As most of the foreign workers came from Indonesia, Nepal, Myanmar, India, Vietnam and Bangladesh, where there are lower exchange rate, they are not able to speak or understand the local language in order to communicate with their superiors and this could affect their work in terms of delay and safety measures [5].

Wei and Yaznifard [6] stated that this language barrier is a problem in the Malaysian construction industry, especially when the supervisors provide instructions to be carried out by the foreign workers because their access to English language is inadequate. It becomes more problematic when the project gets more 
complicated because they are unable to achieve the level of effective communication needed to carry out the project tasks [4]. Salleh, Nordin and Rashid [7] also agree that the language barrier becomes more difficult when the foreign workers are not able to comprehend the instructions.

Besides from inability to carry out project tasks due to poor communication skills, it could also lead to several other effects that could majorly affect construction projects. According to Emuze and James [8], the progress of construction projects could have slowed down due to poor communication, which could also affect the success of the projects in terms of timeframe, budget and could also cause dispute between shareholders. Poor communication may also cause reworks throughout the project which takes time and cost and this could lead to undesirable consequences. Gamil and Rahman [1]; Marhani, et al. [9] also has similar view, where they stated that poor communication could lead lower productivity and work quality which could lead to failure of the projects.

\section{LITERATURE REVIEW}

\subsection{Demand of foreign workers in Malaysia}

Malaysia, a country with a population of 31 million and an unemployment rate of about 4.8 percent in November 2020 recorded by Department of Statistics, Malaysia (DOSM) [10], is in need of foreign workers to fill the manpower gap, especially in the construction industry since locals are not keen on working in this industry. The rapid growth of Malaysia's economic development and political stability [11] become the main factor to attract the influx of foreign workers to this country. Figure 1 projects the estimation on demand of foreign workers by Master Builders Association Malaysia (MBAM) [12], the construction industry is expected to need at least 1.995 million on-site foreign workers in 2020.

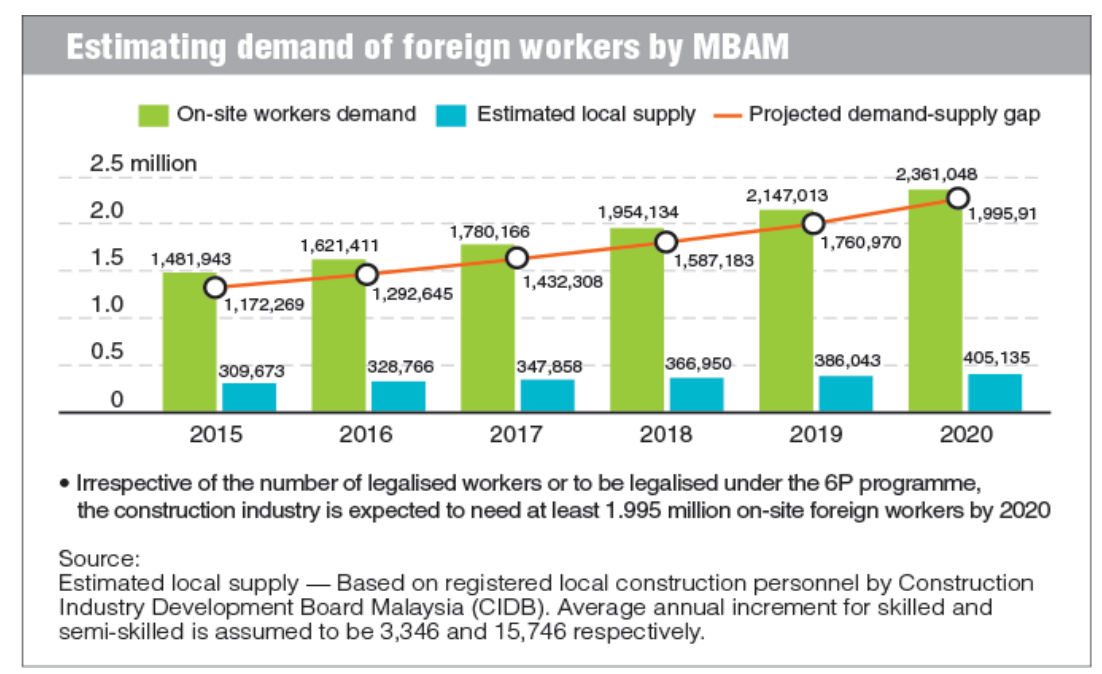

Figure 1. Estimated local supply in construction industry

The opportunity had attracted foreign workers from various nationality mainly Indonesia to Malaysia. Among the many reasons Indonesian foreign workers might be able to adapt locally is the language gap between Malay language (Bahasa Malaysia) and Indonesian language that show some similarities. However, the workforce does not only consist of Indonesian but is made up of many other foreign workers from within Asia. There are also foreign workers of other nationalities such as Bangladesh, Thailand, Philippines, Pakistan, Vietnam and others [10], [13] due to positive productivity effect. This variety of nationality creates diversity within construction site in terms of culture and language, with language being the crucial factor for communication while conducting works.

Figure 2 reports a total of 2,059,382 legally registered foreign workers recorded as of May 31, 2019 to work in Malaysia [14]. The highest percentage of foreign workers recorded based on source from Immigration Department statistics in Housing and Local Government Ministry was from Indonesia $(726,158$ or $35.26 \%$ ) followed by Bangladesh (584,518 or 28.38\%), Nepal (327,529 or 15.9\%), Myanmar (125,675 or $6.10 \%$ ), India $(120,639$ or $5.86 \%)$ while the rest had registered below 60,000 foreign workers from other countries (Figure 2). As stated by Gentile [15], Malaysia has benefited from the high migrant workers through foreign exchange rates, standard of living of the local and reduction of domestic unemployment. 


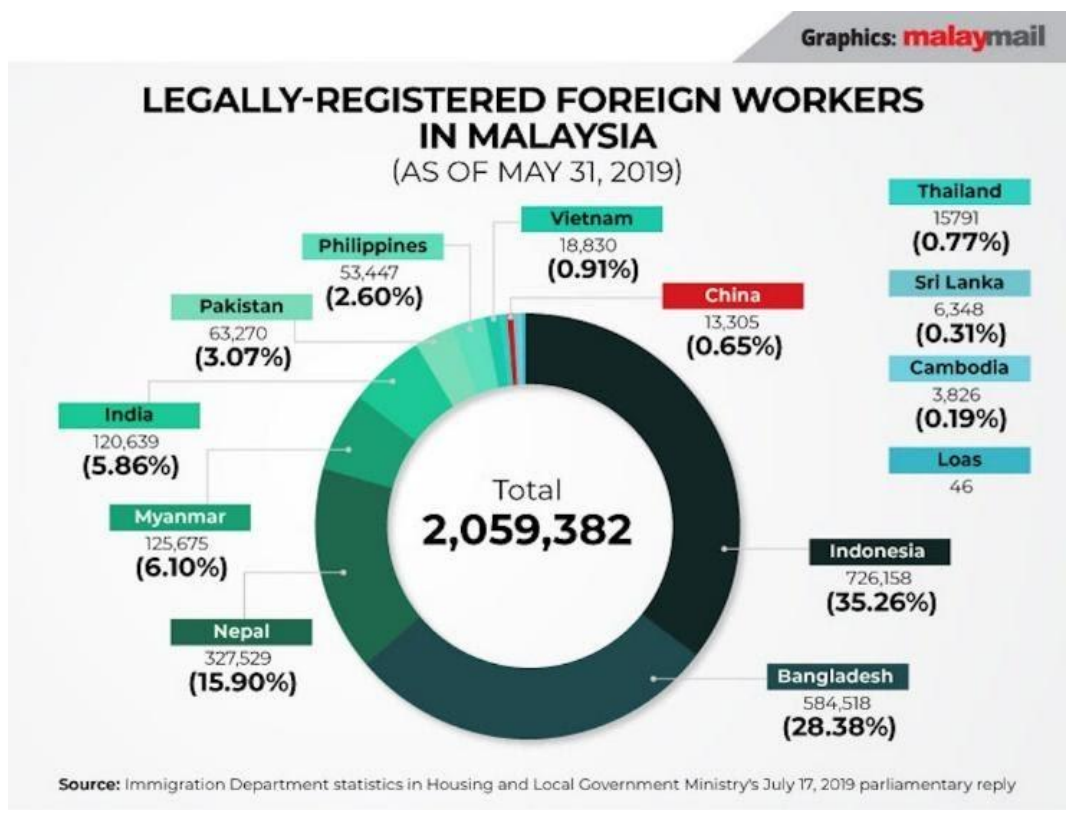

Figure 2. Registered foreign workers in Malaysia

\subsection{Communication}

Communication is an important aspect in our daily life. As the world progresses towards industrialization and technological innovation, the need to communicate and obtain information from all fields is in a great demand [16]. Society needs communicative abilities to interact with each other, to pass on information, as well as to share knowledge. Good communication is considered as a learned skill [17] and this skill benefits individuals in so many ways. One of the advantages is the ability to have the ideas, opinions, thoughts, or knowledge to be delivered and shared effectively. Should the communication process failed, trouble might occur that will deter the effectiveness of the information to be delivered or shared.

In recent years, issues pertaining the use of English language had become a major concern [18], not only Malaysia but also too many developed and developing countries. Although Malay language has been the official national language in Malaysia, there is no less importance given to English language either. According to Pek, et al. [19], non-English countries faced language barrier in Malaysia. As an international language, it is very crucial for one to at least being able to communicate in English, be it in casual or formal setting. According to Ahmed [20], if an individual is able to have a good command of English, it will be an access to any part of the world as English is a language that is being practiced worldwide.

Effective communication has proved to be challenging with people of different cultures [21]. One of the most prominent factors of inability to be proficient in English among foreign workers can be due to very minimal use or practice of the language. Besides, the ever-growing demand of using mobile application had affected the way who people communicate [22], [23]. Using English as the main medium of instruction will not provide users with various advantages. Not only the knowledge of the lesson is being delivered, but the users will also get to improve on their English language skills, mainly speaking. Practicing the language in various contexts will help learners in improving the competency. The hesitance towards speaking English can be contributed by numerous factors. Fear of mistakes, shyness, anxiety, lack of confidence, and lack of motivation all fall under the psychological factors that hinder foreign workers from being communicative capable [24].

\subsection{Language and culture}

Language and culture are fundamental barriers that hinder cross-cultural communication between people [25]. As socio-cultural context plays an important role in determining one's proficiency in English language, the presence of multiple variables such as books, foreign radio, internet, films, and newspaper and magazines contributed to the differences occurred in a language [26]. According to Ahmadi and Bajelani [27], in terms of learning process, English for specific purposes (ESP) has no different from other teaching processes. There is no account for differences between educational processes even though contents in ESP differ from those of general English. Therefore, the focus of ESP is not entirely on the occupational communication but also encompasses all types of communication in a cross-cultural setting. 
The number of people using English language for occupational environment has increased to a greater extent [28]. As far as foreign workers are concerned, their aim is to work according to the specified orders required by their customers. In order to do so, they must be competent in the English language as the industry they are involved in would expect them to understand terms related to their respective job industry. Many problems arose in workplace were results of the barriers cultural diversity imposed on cross cultural communication [21]. With these barriers go untreated will then affect the productivity of an organization in long run.

It is the most important feature for the foreign workers to be able to read from printed materials as well as to understand the instructions provided for actions to be taken. Manuals, instructions, and invoices are going to be a norm throughout their career in the construction sector. According to Olanrewaju, et al. [3], productivity on the site depends very much on effective communication among the workers. Problems that lead to communication barriers which hinder project performance and on-site productivity need to be addressed early. Once these communication barriers are addressed, Sapar and AbuIsaac [25] stated only then the organizational performance will increase.

\section{RESEARCH METHOD}

A survey research was used as the research design in this study. The questionnaire was developed based on a review of literature and adapted from Salleh, Nordin and Rashid [7]. Purposive sampling was use to enquire 26 on-site contractors from different construction companies. The administration of the questionnaire on Google forms was carried out online through social media. An invitation to complete the online questionnaire was sent to the respective respondents to elicit their feedback on language barriers faced by foreign workers in Malaysia construction sites. The information gathered was then analyzed. The data was analyzed by using statistical package for the social sciences (SPSS) software in calculating the mean scores and standard deviation for each question. The results were displayed in the form of tables according to the sections.

\section{RESULTS AND DISCUSSION}

\subsection{Project background}

A total of 17 respondents representing $65.4 \%$ had stated that their company hired workers from Indonesia. While the highest percentage of recruitment was seen on the Bangladeshis nationality which were hired by 26 companies to work at construction sites around Malaysia. This was followed by a total of $23.1 \%$ of respondents from six companies stated that they hired foreign workers from Pakistan. The recruitment of foreign workers by construction companies is shown in Figure 3.

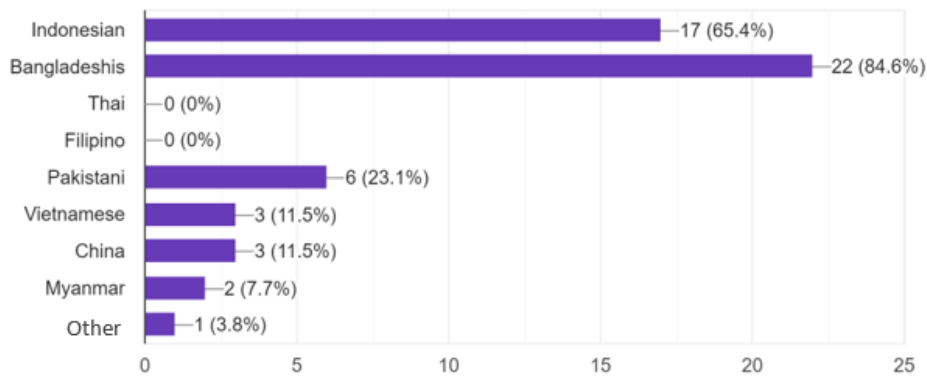

Figure 3. Recruitment of foreign workers

There was a similar number of companies with $11.5 \%$ (three construction companies) that responded to have recruited foreign workers from Vietnam and China respectively. While two construction companies (7.7\%) stated that foreign workers form Myanmar were hired to work at their site project. As there was one (3.8\%) construction company that stated to have hired foreign workers from other countries listed.

As referred to the registered foreign workers in Malaysia [14] as in Figure 2 released by immigration department statistics in housing and local government ministry, foreign workers working at construction sites around Malaysia were relatively high. The majority of construction companies in Malaysia hired foreign workers to work at construction sites. Hence, it was an upmost importance for researchers to identify the nationality of all those foreign workers through the responses from site supervisors and contractors. 


\subsection{Language barriers among foreign workers}

Language barriers has become a threat to the workforce at the construction sector. Various effects are expected to increase the risks and safety of foreign workers at the construction sites. Therefore, Table 1 shows the results of language barriers among foreign workers working at construction sector in Malaysia. Questions varied in overall effect, progress in time, risk in quality, possibilities of wastage, safety compliance and risks towards accidents and injuries.

Table 1. Language barriers among foreign workers at construction industry

\begin{tabular}{lcc}
\hline \multicolumn{1}{c}{ Items } & Mean & Std. deviation \\
\hline Miscommunication delays project completion & 1.08 & .272 \\
Miscommunication risks quality of work & 1.04 & .196 \\
Miscommunication puts foreign workers at higher risk & 1.08 & .272 \\
Miscommunication leads to wastage of materials and resources & 1.08 & .272 \\
Clear instruction reduces wastage & 1.12 & .326 \\
Foreign workers with low language fluency should not be handed important details & 1.12 & .326 \\
Foreign workers with low language fluency could comply to safety regulations & 1.31 & .471 \\
\hline
\end{tabular}

As seen in Table 1, respondents were asked if 'Miscommunication delays project completion' and the feedback showed a Mean score of 1.08 ( $\mathrm{SD}=0.272$ ). This indicated that majority of the respondents strongly agree with the statement that miscommunication created misunderstanding and therefore delayed the time taken for complete a project. On the next item of 'Miscommunication risks quality of work' indicated a Mean score of 1.04 ( $\mathrm{SD}=0.196)$. From the data collected had shown that 25 out of 26 responses agreed that miscommunication occurred from misinterpreting the instructions increased the risk upon the quality of work at construction site.

As for 'Miscommunication puts foreign workers at higher risk' jotted a Mean score of 1.08 (0.272) where respondents did agree that work which requires attention to details put foreign workers at risk towards accident as compared to those with safety knowledge. While in the following item of 'Miscommunication leads to wastage of materials and resources' showed a Mean score of 1.08 ( $\mathrm{SD}=0.272$ ) with majority of the respondents strongly agree that miscommunication from misunderstanding the instruction can lead to wastage of materials and resources.

In responding to the above statement, 'Clear instruction reduces wastage' indicated a Mean score of $1.12(\mathrm{SD}=0.326)$ where respondents agreed that wastage can be reduced if proper instructions are made clear to the foreign workers. On the next item of 'Foreign workers with low language fluency should not be handed important details' showed a Mean score of $1.12(\mathrm{SD}=0.326)$. This indicated that details were not recommended to be handed to foreign workers without fluency in the target language which can put them at risk.

Finally, the item of 'Foreign workers with low language fluency could comply with safety regulations' had elicited a mixed feedback from the respondents with a Mean score of 1.31 ( $\mathrm{SD}=0.471$ ). Respondents were generally agreed and disagreed with the statement of whether foreign workers with little understanding on the target language could fully comply with the set safety regulations.

Hence, based on the findings presented above, Malaysia had since recruited foreign workers to accommodate the needs of rapid development [29]. With the alarming demand of foreign workers, this had somehow overcome the shortcoming from local Malaysian's workforce filling the vacancies in the development industry. In Malaysia, English language has always been recognized as a second language after Malay language (Bahasa Malaysia). Workers equipped with knowledge of English language are sought after by many employers [30] especially in the field of construction industry. Language issue among foreign workers is not new to many organizations, especially in construction sector. This was mainly because of workers portrayed themselves to be lacked confidence in communication, lacked knowledge and poor time management in performing tasks given in the required language [31].

Due to the inability for foreign workers to communicate well in English, many construction companies faced numerous challenges [5], [7] to sustain and deliver on time. As noted in the findings, ineffective communication caused delays in delivery of work done and many times re-work had to be done to achieve the required standard. Hence, companies suffered losses both in profit margin as well as contracts from projects [32] and could not compete with other industry players. The foreign workers are lacking too much in all the four skills which will be applied by the researcher in this course. Results had shown that there are needs to address the language issue among foreign workers in order to stay competitive in the said industry. Without proper understanding of the required language proficiency could put these foreign workers at risk as well as causing unnecessary wastage of time and resources [33].

Int J Eval \& Res Educ, Vol. 10, No. 2, June 2021: 476 - 482 


\section{CONCLUSION}

As a recommendation for this study, we have come to realize that many cases in construction projects which have asked for extension of time (EOT) or else the projects are too neglected due to inability for construction companies to complete the project on time. Therefore, undertaking communication ability as one of the factors affecting the success and failure of a project, further studies need to be carried out to look within the communicative barriers that occur. The findings posted a need do research within language corpus and language training to be carried out to mitigate miscommunication within construction industry. Development of modules for foreign workers training should be conducted before being allowed to move straight into order taking in said projects. Through these, ways to ensure Malaysian construction projects sustain and to have lower risk of negligence.

\section{ACKNOWLEDGEMENTS}

Authors would like to thank SEMESTA-MBI for funding this study. This work was supported by Universiti Selangor (UNISEL) under Grant Nos. I/SEM-MBI/SS/2020/20.

\section{REFERENCES}

[1] Y. Gamil and I. A. Rahman, "Identification of causes and effects of poor communication in construction industry: A theoretical review," Emerging Science Journal, vol. 1, no. 4, pp. 239-247, 2017.

[2] B. Y. Renault and J. N. Agumba, "Risk management in the construction industry: A new literature review," MATEC Web of Conferences, vol. 66, pp. 1-6. 2016.

[3] A. L. Olanrewaju, S. Y. Tan, and L. F. Kwan, "Roles of communication on performance of the construction sector," Procedia Engineering, vol. 196, pp. 763-770, 2017

[4] S. Günhan, G. Şenol and S. Z. Doğan, "Non-verbal cues: Improving communication in construction projects," Proc. of ASEE Annual Conf. and Exposition, 2012, pp. 1-8.

[5] A, Valitherm, "Communication Barrier in Malaysia Construction Sites," International Journal of Education and Research, vol. 2, no. 1, pp. 1-10, 2014

[6] W. M. Wei and R. Yazdanifard, "The Review of Challenges Foreign Workers Face in Construction Industry of Malaysia," Global Journal of Management and Business Research, vol. 15, no. 4, pp. 13-16, 2015.

[7] N. A. B. Salleh, N. B. M. Nordin, and A. K. B. A. Rashid, "The language problem issue among foreign workers in the Malaysian construction industry," International Journal of Business and Social Science, vol. 3, no.11, pp. 97-99, 2012.

[8] F. Emuze and M. James, "Exploring communication challenges due to language and cultural diversity on South African construction sites," Acta Structilia, vol. 20, no. 1, pp. 44-65, 2013.

[9] M. A. Marhani, H. Adnan, H. E. Baharuddin, M. R. Esa, and A. A. Hassan, "Dependency of foreign workers in Malaysian construction industry," Built Environment Journal, vol. 9, no. 1, pp. 39-50, 2012.

[10] Department of Statistics, Malaysia (DOSM), "Key Statistics of Labour Force in Malaysia, November 2020," 11 January 2021, Retrieved from https://www.dosm.gov.my.

[11] I. S. Hamzah, M. R. Sarifin, M. S. A. Aziz, and M. F. A. Abdullah, "Malaysia as Attraction of International Foreign Workers," Journal of Critical Reviews, vol. 7, no. 8, pp. 797-804, 2020.

[12] Master Builders Association Malaysia (MBAM), "Freeze on Foreign Workers' Intake Will Impact Projects," The Edge, easymanpower.co, 2020. [Online]. Available: https://easymanpower.co/malaysia-freeze-foreign-workersintake-will-impact-projects/

[13] J. A. Jordaan, "Foreign workers and productivity in an emerging economy: The Case of Malaysia," Review of Development Economics, vol. 2, no. 1, pp. 148-173, 2018.

[14] I. Lim, "Are fears over China's citizens in Malaysia justified? What the numbers tell us," Malay Mail, 2020. [Online]. Available: https://malaysia.news.yahoo.com/fears-over-china-citizens-malaysia-040025623.html

[15] E. Gentile, Skilled Labor Mobility and Migration: Challenges and Opportunities for the ASEAN Economic Community. United Kingdom: Edward Elgar Publishing, 2019.

[16] L. S. Pek and R. W. M. Mee, "Selfie: Engaging life experiences into writing," Malaysian Journal of Distance Education, vol. 17, no. 2, pp. 51-66, 2015.

[17] M. R. Markovic and A. Salamzadeh, "The Importance of Communication in Business Management," Proceedings of the 7th International Scientific Conference on Employment, Education and Entrepreneurship, Belgrade, Serbia, 2018.

[18] R. W. M. Mee, T. S. T. Shahdan, M. R. Ismail, K. A. Ghani, L. S. Pek, W. Y. Von, A. Woo, and Y. S. Rao, "Role of gamification in classroom teaching: Pre-service teachers' view," International Journal of Evaluation and Research in Education (IJERE), vol. 9, no. 3, pp. 684-690, 2020.

[19] L. S. Pek, R. W. M. Mee, N. T. M. Nadarajan, A. R. Mohamad, Z. Alias, and M. R. Ismail, "Tourists' Perceptions on Multilingualism use among Tourism Employees at Major Attractions in Kuala Selangor," International Journal of Academic Research in Business and Social Sciences, vol. 9, no. 5, pp. 914-919, 2019.

[20] S. Ahmed, "Attitudes towards English Language Learning among EFL Learners at UMSKAL," Journal of Education and Practice, vol. 6, no. 18, pp. 6-16, 2015.

[21] R. D. Jenifer and G. P. Raman, "Cross Cultural Communication Barriers in Workplace," International Journal of Management, vol. 6, no. 1, pp. 332-335, 2015. 
[22] A. C. P. Poh, W. Y. Ung, and T. S. Y. Tan, "The impact of SMS on writing: A case study among university students in Klang Valley," SEGi Reviews, vol. 4, no. 2, pp. 109-124, 2011.

[23] K. F. Ne'matullah, "A Study on The Usage of Abbreviations and Acronyms from WhatsApp Language on Formal English Writing among Diploma TESL Students," National Pre-University Seminar Proceedings, 2017, pp. 105-115.

[24] J. Juhana, "Psychological Factors That Hinder Students from Speaking in English Class (A Case Study in a Senior High School in South Tangerang, Banten, Indonesia)," Journal of Education and Practice, vol. 3, pp.100-110, 2012.

[25] A. A. Sapar and S. R. S. AbuIsaac, "Barriers of Cross-Cultural Communication among Foreign Managers and Staff in Interacting with Malaysian Counterparts," Advances in Social Science, Education and Humanities Research, vol. 154, pp. 210-212, 2015.

[26] S. Shabani and I. Alipoor, "The Relationship between Cultural Identity, Intrinsic Motivation and Pronunciation Knowledge of Iranian EFL Learners," International Journal of Education \& Literacy Studies, vol. 5, no. 2, pp. 61-66, 2017.

[27] A. Ahmadi and M. R. Bajelani, "Barriers to English for Specific Purposes Learning among Iranian University Students," Procedia-Social and Behavioral Sciences, vol. 47, pp. 792-796, 2012

[28] C. N. Chien and M. Hsu, "A case study of incorporating ESP instruction into the university English course," Procedia-Social and Behavioral Sciences, vol. 9, pp. 1885-1888, 2010.

[29] X. D. Carpio, C. Ozden, M. Testaverde, and M. Wagner, "Local Labor Supply Responses to Immigration," The Scandinavian Journal of Economics, vol. 117, no. 2, pp. 493-521, 2015.

[30] S. H. Ting, E. Marzuki, K. M. Chuah, J. Misieng, and C. Jerome, "Employers' Views on The Importance of English Proficiency and Communication Skill for Employability in Malaysia," Indonesian Journal of Applied Linguistics, vol. 7, no. 2, pp. 315-327, 2017.

[31] L. K. Chiu, N. I. Mahat, B. Rashid, N. A. Razak, and H. Omar, "Assessing Students' Knowledge and Soft Skills Competency in the Industrial Training Programme: The Employers' Perspective," Review of European Studies, vol. 8, no. 1, pp.123-133, 2016.

[32] T. Cunningham, "Contractors' Claims for Loss and Expense under the Principle 'Traditional' Forms of Irish Building Contract," Other Resources, vol. 31, pp. 1-41, 2018.

[33] R. Ismail, R. Palliyaguru, G. Karunasena and N. A. Othman, "Health and Safety (H\&S) Challenges Confronted by Foreign Workers in The Malaysian Construction Industry: A Background Study," The 7th World Construction Symposium 2018: Built Asset Sustainability: Rethinking Design, Construction and Operations (Proceedings), 2018, pp. 277-287.

Int J Eval \& Res Educ, Vol. 10, No. 2, June 2021: 476 - 482 